\title{
Analisa Metode AHP Pada Minat dan Bakat Siswa SMA dalam Memilih Jurusan Pada Perguruan Tinggi Di Aceh Tengah
}

\author{
Ira Zulfa' ${ }^{1}$, Richasanty Septima $S^{2}$, Auliadi $^{3}$ \\ Fakultas Teknik Universitas Gajah Putih \\ Blang Bebangka, Takengon \\ ira.zulfea@yahoo.com
}

\begin{abstract}
The AHP (Analytical Hierarchy Process) method is suitable for the decision making process because it can determine scores for each different criteria, then proceed with the best alternative selection process. In the SPK (decision support system) is used web-based that can be accessed anytime, anywhere. So that at school, high school students (high school) can access the system through the school's computer. Requirements analysis is divided into 2 types, namely functional requirements (Functional Requirements) are types of requirements that contain the processes that will be carried out by the system and non-functional requirements (Non Functional Requirements) are types of requirements that contain behavioral properties owned by the system. Criteria for test results is a requirement for decision makers in determining the selection of study programs in Higher Education, based on the DAT test, the results of which are divided into 3 criteria, namely verbal ability, numerical ability, and spatial ability. Of the 100\% accuracy of the results on the system using the AHP method in this system only results in $75 \%$ of the accuracy of the results.
\end{abstract}

Keywords: AHP, SPK, WEB, Senior High School

\begin{abstract}
Abstrak
Metode AHP (Analytical Hierarchy Process) sesuai untuk proses pengambilan keputusan karena dapat menentukan skor untuk setiap kriteria-kriteria yang berbeda, kemudian dilanjutkan dengan proses seleksi alternatif terbaik. Dalam SPK (sistem pendukung keputusan) ini digunakan berbasis web yang bisa diakses kapanpun dan dimanapun. Agar di sekolah, siswa SMA (sekolah menegah atas) bisa mengakses sistem lewat komputer milik sekolah. Analisis dilakukan dengan menentukan kebutuhan sistem. Analisis requirement dibagi menjadi 2 jenis yaitu kebutuhan fungsional (Functional Requirement) adalah jenis kebutuhan yang berisi proses-proses apa saja yang akan dilakukan oleh sistem dan kebutuhan non fungsional (Non Functional Requirement) adalah tipe requirement yang berisi properti perilaku yang dimiliki oleh sistem. Kriteria hasil tes merupakan persyaratan untuk pengambil keputusan dalam menentukan pemilihan program studi di Perguruan Tinggi, berdasarkan tes DAT yang hasilnya dibagi menjadi 3 kriteria yaitu kemampuan verbal, kemampuan numerik, dan kemampuan spasial. Dari 100 \% persentase keakuratan hasil pada sistem penggunaan metote AHP pada sistem ini hanya memperoleh hasil 75\% keakuratan hasil.
\end{abstract}

Kata kunci: $A H P, S P K, W E B, S M A$

\section{PENDAHULUAN}

Pengambilan keputusan yang tepat akan sangat berpengaruh pada masa depan siswa. Permasalahan pengambilan keputusan juga dialami oleh siswa yang ingin melanjutkan pendidikannya ke jenjang yang lebih tinggi. Metode AHP (Analytical Hierarchy Process) sesuai untuk proses pengambilan keputusan karena dapat menentukan skor untuk setiap kriteria-kriteria yang 
berbeda, kemudian dilanjutkan dengan proses seleksi alternatif terbaik. Kriteria di sini bukan berarti bahwa orang tersebut haruslah genius, pintar, bergelar doctor dan sebagainya tetapi lebih mengacu pada orang yang mengerti benar permasalahan yang diajukan, merasakan akibat suatu masalah atau punya kepentingan terhadap masalah tersebut siswa dapat gunakan dengan menentukan kriteria/alasan memilih jurusan yang akan mereka pilih. Dalam sistem pendukung keputusan ini digunakan berbasis web yang bisa diakses kapanpun dan dimanapun. Agar di sekolah, siswa bisa mengakses sistem lewat komputer milik sekolah. Selain itu keuntungan menggunakan web adalah multiplatform, artinya bisa digunakan pada sistem operasi apapun. Bisa diakses dengan sistem operasi Linux, Windows, atau Mac OS, hanya perlu menggunakan browser maka sistem akan berjalan dengan sempurna.

\section{METODOLOGI PENELITIAN}

Pada sistem pendukung keputusan pemilihan program studi di Perguruan Tinggi, siswa melakukan pendaftaran terlebih dahulu (Sign $U p$ ). Adapun urutan prioritas kriteria yang sudah ditetapkan:

a) Kemampuan Verbal

Pada proses ini, siswa dikatakan dominan memiliki kemampuan verbal dengan pemahaman akan hubungan kata, kosakata, dan penguasaan dalam komunikasi. Siswa memiliki kemampuan berpikir kreaktif yang mengukur kelancaran dalam berkomunikasi. Siswa dapat membentuk ide-ide atau gagasan baru berdasarkan informasi yang mencerminkan kelancaran, kelenturan, dan orisinalitas dalam berpikir.

b) Kemampuan Numerik

Pada proses ini, siswa dikatakan dominan memiliki kemampuan numerik adalah siswa memiliki kecermatan dan kecepatan dalam penggunaan fungsi-fungsi hitung dasar dan mengolah perhitungan aritmatika. Kemampuan ini dapat mengungkapkan kemampuan intelektual terutama kemampuan penalaran berhitung dan berfikir secara logis.

c) Kemampuan Spasial

Pada proses ini, siswa dikatakan dominan memiliki kemampuan spasial adalah siswa dapat mengamati hubungan posisi objek dalam ruang, melihat objek dalam berbagai sudut pandang, memperkirakan jarak antara dua titik, dan membayangkat perputaran objek dalam ruang.

Pada Gambar 1. merupakan rancangan sistem flowchart yang akan di terapkan pada program untuk lebih mempermudah siswa untuk memilih jurusan sesuai dengan minat dan bakatnya berikut keterangan sistem: 


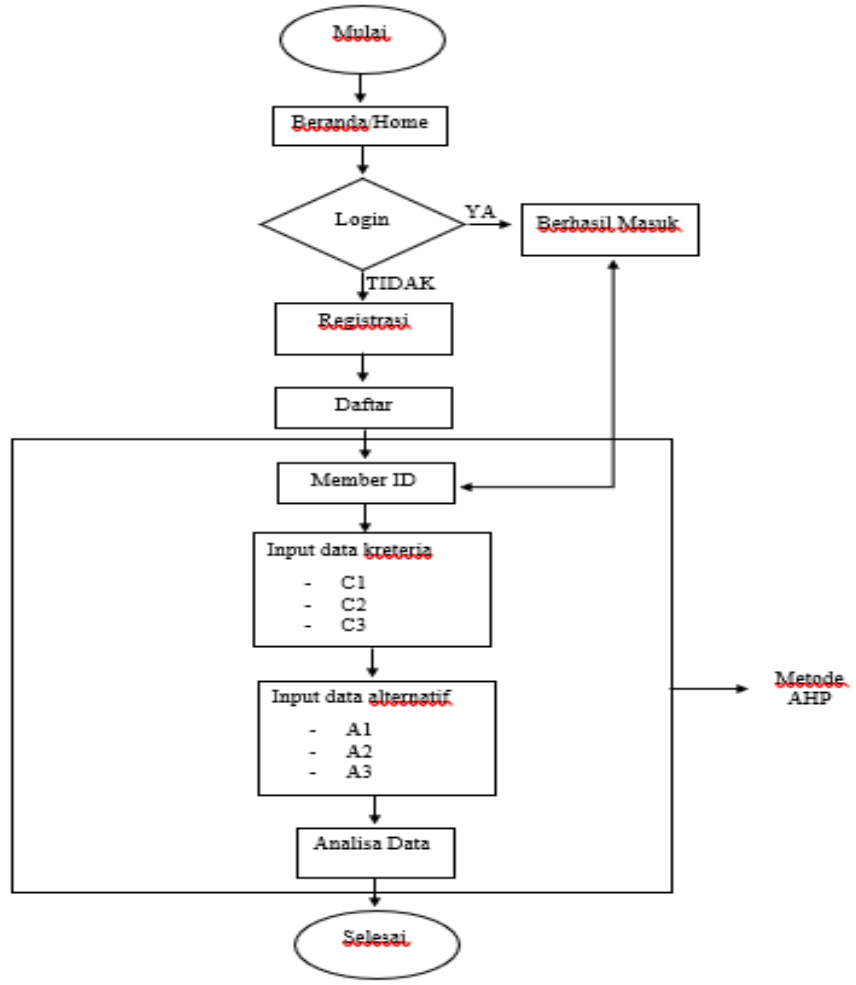

Gambar 1. FlowChart sistem yang di usulkan

Salah satu keutamaan model AHP yang membedakannya dengan model-model pengambil keputusan yang lain adalah tidak adanya syarat konsistensi mutlak. Pengumpulan pendapat antara satu faktor dengan faktor yang lain adalah bebas satu sama lain, dan hal ini dapat mengarah pada ketidakkonsistenan juga tidak diinginkan. Pengulangan pada sejumlah responden yang sama kadang diperlukan apabila derajat tidak konsisten besarnya. Indeks Konsistensi dari matriks berordo $n$ dapat diperoleh dengan rumus:

$\mathrm{C} 1=\frac{(\mathbb{m a x}-n)}{n-1}$

Keterangan:

$\mathrm{C} 1=$ Consistensy Index

MAX = Nilai normalisasi terbesar dari matriks berordo

$\mathrm{N} \quad=$ Ordo matriks

Penentuan kriteria dan perbandingan antar kriteria diperoleh dari jurnal mengenai kriteria bobot berdasarkan hasil wawancara pada Ranu Prima College (RPC). Nilai bobot dari masing-masing kriteria yaitu kemampuan verbal, kemampuan numeric dan kemampuan spasial dibentuk dalam tabel dibawah ini: 
Tabel 1. Simbol Kriteria dan Bobot

\begin{tabular}{|c|l|l|l|l|}
\hline No & \multicolumn{4}{|l}{ Kreteria dan Bobot Skor Alternatif, Jurusan dan Hasil } \\
\hline 1. & Harga & C1 & Sistem Informasi & A1 \\
\hline 2. & Prospek & C2 & Sistem Komputer & A2 \\
\hline 3. & Keinginan & C3 & Teknik Infomatika & A3 \\
\hline
\end{tabular}

Tabel 2. Matriks Perbandingan antar Kriteria

\begin{tabular}{|c|c|c|c|}
\hline Kemampuan & Verbal & Numerik & Spasial \\
\hline Verbal & 1 & 3 & 5 \\
\hline Numerik & $1 / 3$ & 1 & 3 \\
\hline Spasial & $1 / 5$ & $1 / 3$ & 1 \\
\hline Total & $\mathbf{1 . 5 3}$ & $\mathbf{4 . 3 3}$ & $\mathbf{9}$ \\
\hline
\end{tabular}

Tabel 3. Matriks Pembobotan Kriteria yang Dinormalkan

\begin{tabular}{|c|c|c|c|c|}
\hline Kemampuan & Verbal & Numerik & Spasial & Bobot \\
\hline Verbal & 0.65 & 0.69 & 0.56 & $\mathbf{0 . 6 3}$ \\
\hline Numerik & 0.22 & 0.23 & 0.33 & $\mathbf{0 . 2 6}$ \\
\hline Spasial & 0.13 & 0.08 & 0.11 & $\mathbf{0 . 1 1}$ \\
\hline
\end{tabular}

Analisis dilakukan dengan menentukan kebutuhan sistem. Analisis requirement dibagi menjadi 2 jenis yaitu kebutuhan fungsional (Functional Requirement) adalah jenis kebutuhan yang berisi proses-proses apa saja yang akan dilakukan oleh sistem dan kebutuhan non fungsional (Non Functional Requirement) adalah tipe requirement yang berisi properti perilaku yang dimiliki oleh sistem.

Tabel 4. Analisis Kebutuhan

\begin{tabular}{|c|l|l|}
\hline No. & $\begin{array}{l}\text { Kebutuhan Fungsional } \\
\text { (Functional Requirement) }\end{array}$ & $\begin{array}{l}\text { Kebutuhan Non Fungsional (Non } \\
\text { Functional Requirement) }\end{array}$ \\
\hline 1. & $\begin{array}{l}\text { Sistem harus dapat melakukan } \\
\text { Login untuk Admin }\end{array}$ & $\begin{array}{l}\text { Sistem dilengkapi dengan password } \\
\text { yang dienkripsi pada proses login } \\
\text { sebagai keamanan sistem. }\end{array}$ \\
\hline 2. & $\begin{array}{l}\text { Sistem dapat merubah dan } \\
\text { menghapus data siswa serta } \\
\text { menyimpan data ke database }\end{array}$ & $\begin{array}{l}\text { Sistem dapat memberikan informasi } \\
\text { jika user salah dalam memasukkan } \\
\text { username dan password. }\end{array}$ \\
\hline 3. & $\begin{array}{l}\text { Sistem dapat melakukan } \\
\text { penyelesaian dengan metode } \\
\text { AHP. Melakukan proses } \\
\text { perhitungan dengan bobot. }\end{array}$ & $\begin{array}{l}\text { Sistem dapat memberikan } \\
\text { kesempatan bagi siswa untuk } \\
\text { melakukan tes ulang }\end{array}$ \\
\hline 4. & $\begin{array}{l}\text { Sistem dapat menampilkan hasil } \\
\text { seleksi pemilihan program studi } \\
\text { sesuai } \\
\text { kemampuan minat bakat siswa }\end{array}$ & $\begin{array}{l}\text { Sistem mudah digunakan atau } \\
\text { bersifat user friendly }\end{array}$ \\
\hline
\end{tabular}




\section{HASIL DAN PEMBAHASAN}

Kriteria hasil tes merupakan persyaratan untuk pengambil keputusan dalam menentukan pemilihan program studi di Perguruan Tinggi, berdasarkan tes DAT yang hasilnya dibagi menjadi 3 kriteria yaitu kemampuan verbal, kemampuan numerik, dan kemampuan spasial. Menentukan susunan prioritas elemen adalah dengan menyusun perbandingan berpasangan yaitu membandingkan dalam bentuk berpasangan seluruh elemen untuk setiap sub hirarki. Perbandingan tersebut ditransformasikan dalam bentuk matriks. Contoh, terdapat $\mathrm{n}$ objek yang dinotasikan dengan $\left(A_{1}, A_{2}, \ldots, A_{n}\right)$ yang akan dinilai berdasarkan pada nilai tingkat kepentingannya antara lain $\mathrm{Ai}$ dan $\mathrm{Aj}$ dipresentasikan dalam matriks Pair-Wise Comparison.

Tabel 5. Matriks Perbandingan Berpasangan

\begin{tabular}{|c|c|c|c|c|}
\hline & $\mathrm{A}_{1}$ & $\mathrm{~A}_{2}$ & $\ldots$ & $\mathrm{A}_{\mathrm{n}}$ \\
\hline $\mathrm{A}_{1}$ & $\mathrm{a}_{11}$ & $\mathrm{a}_{12}$ & $\ldots$ & $\mathrm{a} 1 \mathrm{n}$ \\
\hline $\mathrm{A}_{2}$ & $\mathrm{a}_{21}$ & $\mathrm{a}_{22}$ & $\ldots$ & $\mathrm{a} 2 \mathrm{n}$ \\
\hline$\ldots$ & $\ldots$ & $\ldots$ & $\ldots$ & $\ldots$ \\
\hline $\mathrm{A}_{\mathrm{n}}$ & $\mathrm{a}_{\mathrm{n} 1}$ & $\mathrm{a}_{\mathrm{n} 2}$ & $\ldots$ & $\mathrm{a}_{\mathrm{nn}}$ \\
\hline
\end{tabular}

Nilai $a_{i j}$ adalah nilai perbandingan elemen $A_{i}$ (baris) terhadap elemen $A_{j}$ (kolom) yang menyatakan hubungan:

a) Seberapa jauh tingkat kepentingan $A_{i}$ (baris) terhadap kriteria $C$ dibandingkan dengan $A_{j}($ kolom) atau

b) Seberapa jauh dominasi $A_{i}$ (baris) terhadap $A_{j}($ kolom) atau

c) Seberapa banyak sifat kriteria $C$ terdapat pada $A_{i}$ (baris) dibandingkan dengan $A_{j}(k o l o m)$

Berikut adalah implementasi program sesuai dengan rancangan yang sebelumnya telah dibuat, antara lain :

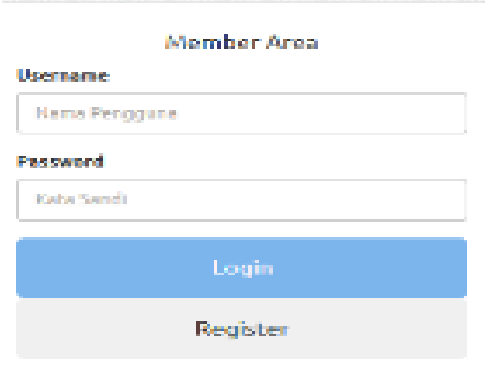

Gambar 2. Tampilan Login

Laman login berfungsi untuk bisa masuk dan menakses sistem ini bagi yang sudah memiliki akun sebelumnya. 


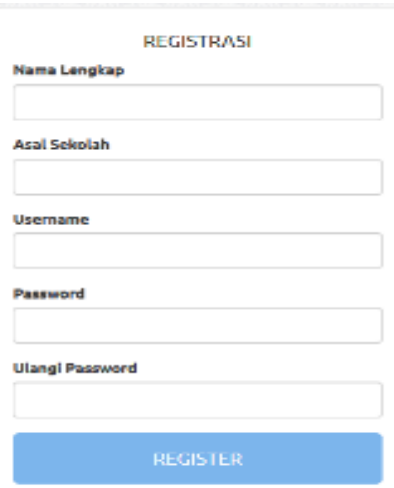

Gambar 3. Tampilan Daftar

Laman daftar berfungsi untuk mendaftarkan data diri user bagi yang ingin login tetapi belum memiliki akun sebelumnya.
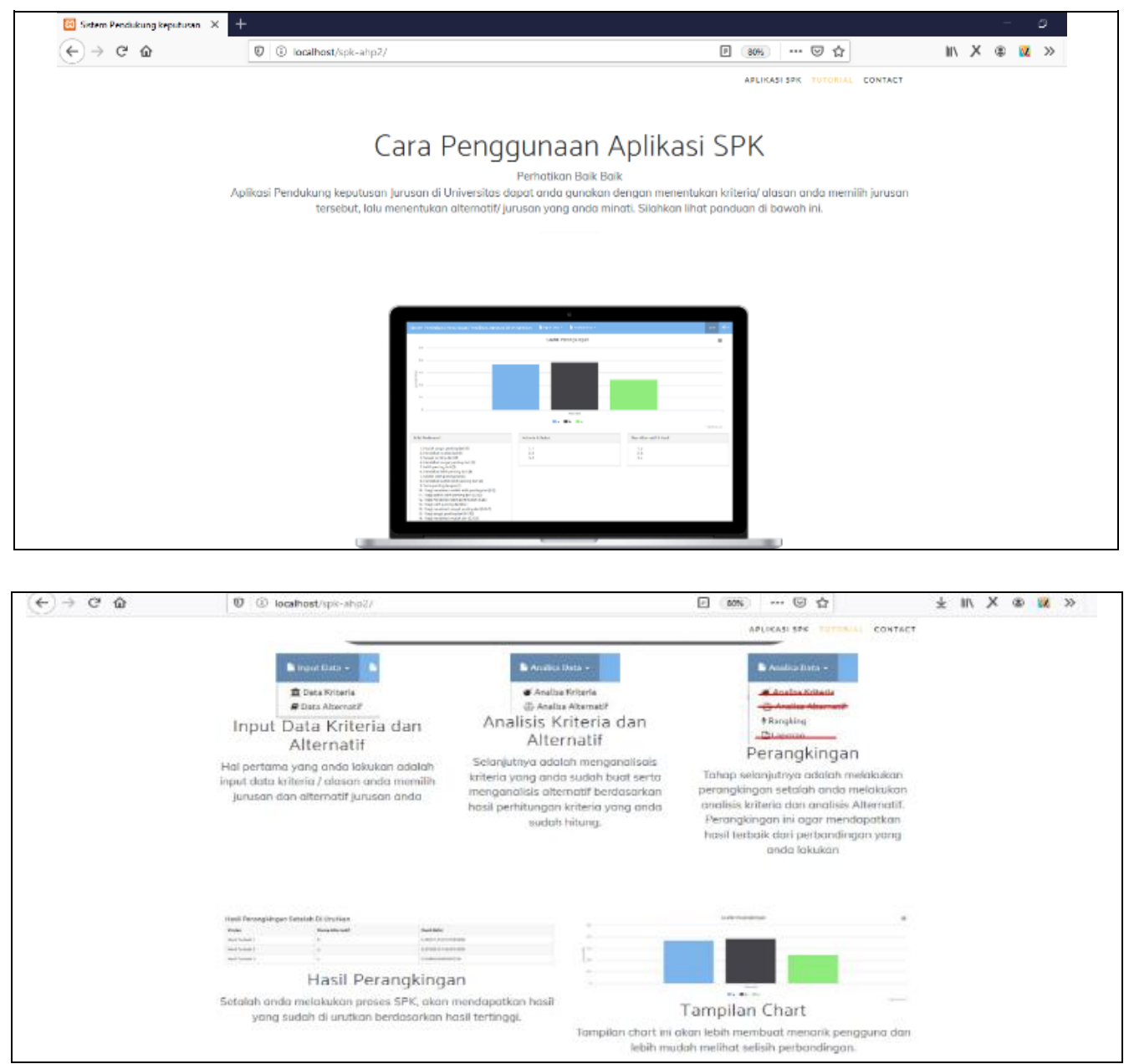

Gambar 4. Tampilan Beranda

Laman ini merupakan laman utama yang berfungsi untuk menampilkan tampilan menu-menu yang disediakan sistem. 


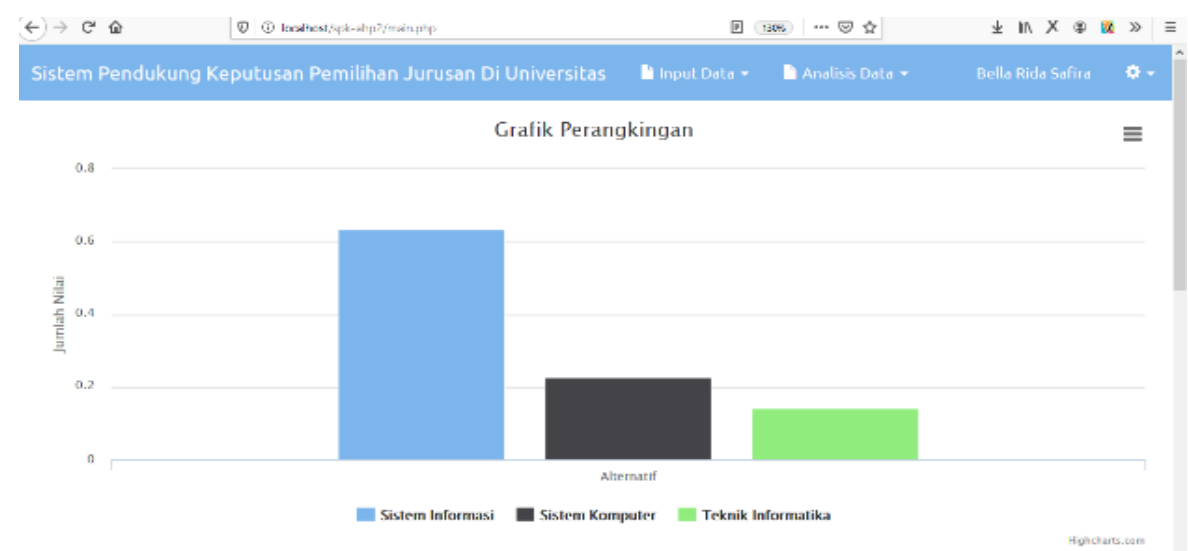

Gambar 5. Tampilan Hasil Pemilihan Jurusan

Laman ini berfungsi menampilkan hasil jurusan yang dipilih sesuai dengan keminatannya yang ditampilkan dalam bentuk grafik.

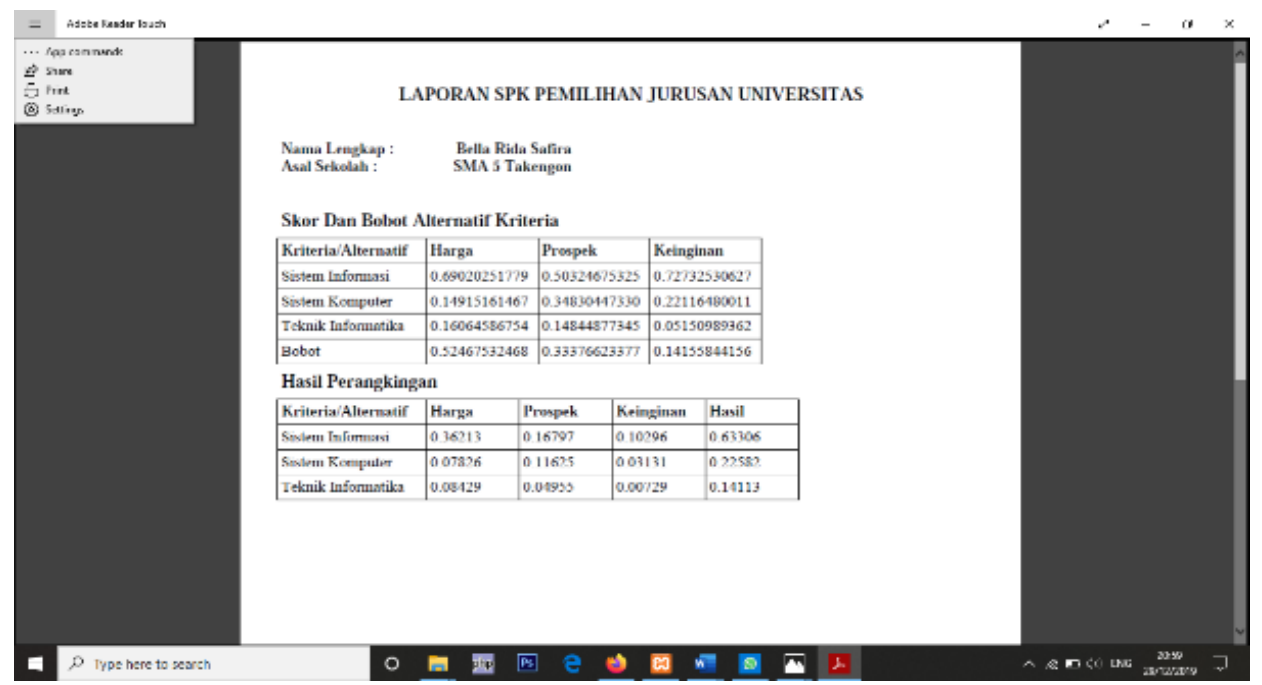

Gambar 6. Tampilan Hasil Laporan Perangkingan Nilai

Gambar 6 hasil dari perolehan nilai yang telah dihitung dapat dicetak dalam bentuk PDF.

\section{SIMPULAN}

Sistem ini dapat digunakan oleh semua kalagan khususnya siswa kelas 3 SMA yang akan menempuh jejang perkuliahan dan dari $100 \%$ persentase keakuratan hasil pada sistem penggunaan metote AHP pada sistem ini hanya memperoleh hasil 75\% keakuratan hasil.

\section{DAFTAR PUSTAKA}

[1] Raharjo, Heryanto, Rosdiana K, "Modul Pemrograman WEB (HTML, PHP \& MySQL)", Modula, Bandung. 2014. 
Jurnal Sains Komputer \& Informatika (J-SAKTI)

Volume 4 Nomor 1 Maret 2020, pp. 191-198

ISSN: 2548-9771/EISSN: 2549-7200

http://tunasbangsa.ac.id/ejurnal/index.php/jsakti

[2] Satzinger, John W,. Jackson, Robert B., Burd., Stephen D "System Analysis and Design in Changing World". Australia : Cengage Learning. 2016.

[3] Sopian Hardiant. "Membangun Respotte Website Dengan Twitter Boostrap 2.0 Tphp Dan Mysyi", Founder Of Greek House : Bandung. 2014.

[4] Supriatna, Mamat, Budiman, Nandang. "Bimbingan Karir di SMA", 18-22 . 2014.

[5] Wahyu Widyantoro, “ Buku Panduan Bootstrap”, Jakarta : Margotek. 2014. 